\title{
Degradation of Film and Rigid Bioplastics During the Thermophilic Phase and the Maturation Phase of Simulated Composting
}

\author{
Federica Ruggero ${ }^{1,5} \cdot$ Rob C. A. Onderwater ${ }^{2} \cdot$ Emiliano Carretti $^{3} \cdot$ Stéphanie Roosa $^{2} \cdot$ Samira Benali $^{4}$. \\ Jean-Marie Raquez ${ }^{4} \cdot$ Riccardo Gori $^{1} \cdot$ Claudio Lubello $^{1} \cdot$ Ruddy Wattiez $^{5}$
}

Accepted: 15 February 2021 / Published online: 27 February 2021

(c) The Author(s) 2021

\begin{abstract}
The recent regulations, which impose limits on single use plastics and packaging, are encouraging the development of bioplastics market. Some bioplastics are labelled as compostable with the organic waste according to a specific certification (EN 13432), however the conditions of industrial composting plants are generally less favourable than the standard test conditions. Aiming at studying the effective degradation of marketable bioplastic products under composting, the current research stresses novel elements which can strongly influence bioplastics degradation: the simulation of industrial composting conditions and the thickness of bioplastic products, ranging between 50 and $500 \mu \mathrm{m}$. The research approaches these critical aspects simulating a composting test of 20 days of thermophilic phase followed by 40 days of maturation phase, on starchbased polymer Mater-Bi® (MB), polybutylene adipate terephthalate (PBAT), polylactic acid (PLA) of different thickness. Conventional low density polyethylene (LDPE) was introduced as negative control. An overall study with Fourier Transform InfraRed (FTIR), ThermoGravimetric Analysis (TGA), Gel Permeation Chromatography (GPC), Scanning Electron Microscope (SEM) and visual inspections was applied. Results highlighted that MB film presented the highest degradation rate, $45 \pm 4.7 \%$ in terms of weight loss. Both MB and PBAT were subjected to physico-chemical features change, while LDPE presented slight degradation signs. The most critical observations have been done for PLA, which is strongly influenced both by thickness and thermophilic phase duration, shorter than the EN 13432 conditions.
\end{abstract}

Keywords Bioplastics $\cdot$ Composting $\cdot$ Degradation $\cdot$ Thermophilic phase $\cdot$ Microplastics

\section{Introduction}

The term 'bioplastic' is intended for a group of materials either biobased, biodegradable, or which features both properties [1]. Bioplastic bags and single use products, such

Federica Ruggero

federica.ruggero@unifi.it; federica.ruggero@dicea.unifi.it

1 Department of Civil and Environmental Engineering, University of Firenze, Via di S. Marta 3, 50139 Florence, Italy

2 Materia Nova ASBL, Avenue du Champ de Mars 6, 7000 Mons, Belgium

3 Department of Chemistry "Ugo Schiff” and CSGI, University of Firenze, Florence, Italy

4 Polymer and Composite Materials Department, University of Mons, 15 Avenue Maistriau, 7000 Mons, Belgium

5 Proteomics and Microbiology Department, University of Mons, Avenue du Champ de Mars 6, 7000 Mons, Belgium as cutleries, dishes and glasses, which are available in the supermarkets, are labelled as compostable in accordance with EN 13432:2000 [2] or other standards, such as ASTM D5338 and ISO 20200 [3, 4]. At the end of the composting treatment, the material becomes compost, an organic soil improvement agent that finds a usage in agriculture; thus, it allows compostable bioplastics to be properly recycled in the perspective of a circular economy and to be part of a sustainable agricultural system [5]. In some countries, compostable bioplastic bags have become the main kind of shopper and garbage bags. For example, in Italy a specific law was enacted by the Government in 2017 to impose the use of biobags for organic waste collection [6]. Moreover, the strict limitations promised in the near future about the usage of single use plastic products and plastic packaging [7] are favouring the change towards the usage of compostable bioplastics also for this kind of products.

It's fair to underline that the conditions for testing bioplastic compostability in accordance with the afore mentioned 
standards, require a minimum period of 45 days at temperatures not lower than $58^{\circ} \mathrm{C}$. Thus, research studies on degradation processes of bioplastics have mostly been carried out in accordance with these conditions [8], which are not strictly representative of highly variable industrial composting conditions.

The current research deviated from the standard tests in order to introduce novel elements in the study of bioplastics degradation, trying to come closer to the conditions of industrial composting process with respect to the operational conditions mentioned in guidelines, and to the effect of the bioplastic thickness.

The lab scale test is carried out with the purpose to simulate the composting process, which is characterized by thermophilic and maturation phases. To select the operational conditions, an overview provided by the European Commission [9], which accounts 17 plants from 6 European countries (Spain, France, Ireland, Italy, Portugal, United Kingdom) was considered. The mean length of the thermophilic phase is 2-3 weeks; just two cases differ from the average, presenting a thermophilic phase of 1 week and 1 month. On the contrary, the maturation phase has a wider variability among the plants: from a minimum of 2 weeks to a maximum of 6 months. Starting from this overview, the thermophilic and the maturation phase in the lab-scale test lasted for 20 days and 40 days respectively. Considering the increasing trend of bioplastics usage [10], the input of the tested material has a concentration slightly higher than in the standard tests. Further element of novelty was related to the selection of the type and the thickness of the tested bioplastics. Indeed, they are strictly related to the usage of bioplastic products: Mater- $\mathrm{Bi}{ }^{\circledR}(\mathrm{MB})$, a starch-based biopolymer, is widely employed for biobags production, while generally polylactic acid (PLA) is used for single use glasses, cutleries and dishes manufacturing. These products have a thickness ten times higher than film bags.

In the degradation monitoring, the key criteria highlighted by the methodologies applied in accordance with the common guidelines, is the weight loss. Though, this parameter has some limitations: (i) the visual recoverability of the entire sample due to the disintegration into micro-pieces, (ii) the variables that influence the weight (compost residues on plastic surface and water absorbed during composting), and finally (iii) the complexity of the degradation process which cannot be addressed. Based on these considerations, the current research proposes the study of the plastic degradation process in industrial composting conditions with a wide range of methodologies, enabling to provide insight into the chemico-physical changes of the tested polymers and to define the key drivers of the degradation steps.

The degradation of a polymeric material includes several steps and the process can stop at each stage [11]. The biopolymer is a complex material which cannot enter the bacterial cell walls: biodeterioration is the first step occurring, which ensures the fragmentation of the material into a millimetre structure and the appearance of cracks and fissures. The bioplastics present weakness, discoloration erosion signs and polymer splitting [12]. Then, due to its easier biodegradable potential and its tiny structure, the second step can occur: the depolymerization will generate a mixture of oligomers and monomers. The energy for the scission of the chemical bonds during this step may have different origins. In fact, a combination of abiotic and biotic factors contribute in both biodeterioration and depolymerization steps [13].

The main abiotic factors are mechanical, physical and chemical. Mechanical factors (e.g. stresses, weathering), cause damages, sometimes visible at microscopic level more than macroscopically. Temperature can cause partial melting of a material and a change in the disorganization of chains, facilitating the further accessibility to chemical and biological degradation [14]. Moreover, among the chemical factors, oxygen is the most powerful agent to induce degradation of the material by attacking covalent bonds and producing free radicals. Water splits polymers containing hydrolysable covalent bonds into groups of ethers, esters, anhydride and so forth. Oxidative and hydrolytic degradations are more easily performed within disorganised molecular regions (amorphous). Finally, UV irradiation which generally causes different levels of chemical weathering in dependence on the environment [15].

Considering the biotic factors, microbial species can adhere to polymer surface due to the secretion of an adhesive glue which is a complex matrix made of polysaccharides and proteins. The bacterial aggregation which is attached to the polymer surface through this matrix is visible with SEM and often referred to as a biofilm. It can produce disruption and erosion of the polymeric surface, but also infiltrates into cracks and pores increasing their size and weakening the mechanical strength of the polymer [16]. An important role in the biotic degradation is played by the enzymes synthetized by microorganisms. They are responsible for the breakdown of specific bonds in a polymer [11]. In literature some authors adopt a nomenclature with the abbreviate name of the polymer followed by "depolymerase" [13].

The oligomers and monomers generated from the previous steps go through the cellular membranes and are integrated inside the microbial metabolism (assimilation) to produce energy, new biomass as well as simple and complex metabolites which may be excreted and reach the extracellular surroundings [17].

The current research has the objective to investigate the biotic and abiotic degradation of various bioplastics commonly used for film and rigid manufacturing under composting conditions which reflect full scale composting plants. 


\section{Materials and Methods}

\section{Tested Materials}

The bioplastics selected for the experimental tests are present on the European market and are products commonly used by citizens and disposed in the organic fraction of waste. Three bioplastic types have been selected. The first one is a starch-based copolymer widely employed for biobags production, which is known as Mater-Bi ${ }^{\circledR}(\mathrm{MB})$. MB bags are commercially available and were bought in Italian supermarket; they were manually cut (thickness $=50 \mu \mathrm{m}$, size $=5 \times 5 \mathrm{~cm}$, melt temperature $=64{ }^{\circ} \mathrm{C}$, density $\left.=1.28 \mathrm{~g} / \mathrm{cm}^{3}\right)$. The material is composed of starch (20\%), polybutylene adipate terephthalate (PBAT) $(70 \%)$ and some additives (10\%) [18]. It was found in previous study that PBAT seems to be the most critical part of $\mathrm{MB}$, because its degradation is largely influenced by composting process conditions (especially low humidity and short thermophilic phase) [19]. Therefore, pure PBAT is separately tested to better investigate its degradation process. PBAT Ecoflex ${ }^{\circledR}$ F Blend $\mathrm{C} 1200$ was supplied by BASF (thickness $=90 \mu \mathrm{m}$, size $=5 \times 5 \mathrm{~cm}$, melt temperature $=110-120^{\circ} \mathrm{C}$, density $=1.25-1.27 \mathrm{~g} / \mathrm{cm}^{3}$. The third material is polylactic acid (PLA). However, differently from MB and PBAT, it is tested in rigid form, in order to simulate the degradation of some thick products made of PLA and widely diffused on the market, such as single use cutleries, dishes and glasses. It was supplied by NatureWorks LLC (USA): PLA98.6/1.4 (L/D-lactide) is a grade for the extrusion of films ( $\mathrm{D}$-isomer $<1.4 \%$; relative viscosity $=3.94$; residual monomer $=0.14 \%$, melt temperature $=210 \pm 8{ }^{\circ} \mathrm{C}$ ). Pellets are dried in vacuum oven overnight at $60{ }^{\circ} \mathrm{C}$ and processed using a press model 4122CE manufactured by Carver, with circle shape (thickness $=500 \mu \mathrm{m}, \varnothing=5 \mathrm{~cm}$ ). Due to the thickness, the surface area of PLA is much lower than that of film MB and PBAT. Therefore, a direct comparison between the materials is not made in the present study.

Low density polyethylene (LDPE) in film form was introduced in the test as a negative control for its low biodegradation efficiency. Furthermore, as some LDPE garbage bags are incorrectly conferred to industrial composting plants, an improvement of the knowledge about their fate in composting conditions could rise the need to provide stricter limits regarding the use of LDPE bags for organic waste collection. LDPE film ET311350/2 was bought from Goodfellow company (UK) (thickness is $=250 \mu \mathrm{m}$, size $=5 \times 5 \mathrm{~cm}$, melt temperature $=116^{\circ} \mathrm{C}$, density $=0.925 \mathrm{~g} / \mathrm{cm}^{3}$ ).

\section{Experimental Set Up}

Composting tests were carried out in accordance with modified guidelines EN ISO 14855-2:2018 [20]. $10 \mathrm{~g}$ of plastic were used, completely mixed in $350 \mathrm{~g}$ of compost (concentration 2.9\%). A 3 months stable compost [Respirometric index 5 days $\left(\mathrm{IR}_{5}\right) 5.6 \mathrm{mg} \mathrm{O} / \mathrm{g} \mathrm{TS}$ ] from green and agricultural waste was provided by Ipalle industrial composting plant, located in Froyennes (BE), together with the chemico-physical analyses carried out by Liège University (BE). Humidity, $\mathrm{C} / \mathrm{N}$ and $\mathrm{pH}$ of compost were 47\%, 15 and 7.5, respectively. Mature compost shall be used as inoculum of the aerobic biomass to provide sufficient diversity of microorganisms and enhance the degradation process of the tested materials.

Composting tests were carried out in three replicates for each material (Figure S1); moreover, three reactors contained only compost as background controls. Glass reactors were cylindrically shaped with a volume of $5 \mathrm{~L}$, manufactured by Pierre E. bvba (Vilvoorde, BE). The reactors are connected with a system provided by Wetlands Biosciences sprl (Louvain-la-Neuve, BE), which allows the automatic control of the air flow through the reactor. The air flow is humidified by passing through distilled water in a glass bottle, of which each reactor is provided. The 15 reactors were placed into two Binder BD400 incubators in order to maintain the conditions required during the test.

The test was carried out under thermophilic conditions $\left(58 \pm 2{ }^{\circ} \mathrm{C}\right)$ for 20 days, followed by a maturation phase $\left(37 \pm 2{ }^{\circ} \mathrm{C}\right)$ for 40 days. Reactors were opened once a week: humidity was checked and manually adjusted to be in the range $50-55 \%$ and the sample was mixed to ensure a proper homogenization of the plastic material within the compost.

Some pieces of the material from each reactor were recovered after 20 and 60 days to be submitted to the chemicophysical analyses in three replicates; before being analysed, the samples were gently brushed off with tissue papers to remove compost residue from their surface.

\section{Fourier Transform Infrared}

The Fourier Transform InfraRed (FTIR) spectra were collected in total reflectance mode (ATR) with Bruker Tensor 27 IR. FTIR-ATR was performed on the bioplastic pieces recovered at the end of composting test, after brushing to remove compost residues attached to the surface. In fact, the analysis was carried out directly on the film surface. The investigated wavenumber range was $4000-500 \mathrm{~cm}^{-1}$ and the resolution was $2 \mathrm{~cm}^{-1}$, with 64 scans performed on each sample. The system was coupled with software 6.5 Opus. The spectra were acquired in absorbance. 


\section{Experimental Weight Loss}

Compost recovered after 60 days of composting was first sieved ( $2 \mathrm{~mm}$ mesh). Plastic pieces both from the over and undersieve were extracted with tweezers, as far as it was possible with a naked eye. They all were brushed off and weighted to be compared with the initial weight $(10 \mathrm{~g})$. Even after brushing, the plastic pieces present some compost attached to the surface; moreover, part of the tested plastics acquire the capability to absorb water during composting process. These two variables could alter the experimental weight of plastic pieces recovered in the end of the test.

To provide an estimation of these variables and subtract them from the experimental weight, information shown by TGA analysis were exploited. Percentage values of water and residues depicted by TGA were used as the two quantities to be subtracted from the experimental weight, resulting in the equation:

Ex.Weight loss $(\%)=\left(100-\left(\frac{W_{60}}{10}\right) * 100\right)-\operatorname{water}(\%)-$ residues $(\%)$ where $W_{60}$ is the experimental weight (g) of the plastic pieces recovered after 60 days of composting, $10 \mathrm{~g}$ is the initial weight of the plastic sample, water (\%) and residues (\%) are the values depicted by TGA analysis, as explained in next paragraph.

\section{ThermoGravimetric Analysis}

ThermoGravimetric analysis (TGA) was performed using a TA Instruments Q-500 (MTG-TGA) apparatus using open aluminium pans under a nitrogen atmosphere. Raw data are graphed in Figures S2-S5. Measurements were performed in a dry nitrogen balance purge flow of $40.0 \pm 0.5 \mathrm{ml} / \mathrm{min}$ and sample purge flow of $60.0 \pm 0.5 \mathrm{ml} / \mathrm{min}$ by increasing the temperature from room temperature up to $800{ }^{\circ} \mathrm{C}$ at $10{ }^{\circ} \mathrm{C} /$ min. $10 \mathrm{mg}$ of samples were submitted to the analysis.

From the first derivative of the TGA curves it is possible to obtain the characteristic temperature associated to the thermal reaction, indicated with $\mathrm{T}_{\text {peak }}$ and corresponding to the maximum temperature reached during the conversion. Moreover, the weight loss of the materials at given aging time can be acquired from the raw data, exploiting the following equations:

$P A(\%)=\int_{T_{0}}^{T_{\text {inf }}} \frac{d w}{d T} d T$ where $T_{0}$ and $T_{i n f}$ are the initial and the final temperatures of conversion, readable in the DTGA graph. The integral corresponds to the peak area, which basically is the weight of the material. Knowing the peak area $(P A)$ of the material before $\left(P A_{0}\right)$ and after degradation $(P A)$, it's possible to get the weight loss $(W L(\%))$.

$W L(\%)=100-\frac{(P A)}{\left(P A_{0}\right)} \times 100$

Finally, the TGA provides values of water absorbed by tested material water (\%) and of residues of compost attached to the plastics surface residues (\%): the temperatures set for the percentage weight of water and residues are $\mathrm{T}<105{ }^{\circ} \mathrm{C}$ and $\mathrm{T}>500{ }^{\circ} \mathrm{C}$, respectively. These two values will be also exploited in the measurement of the experimental weight loss, as discussed previously. Moreover, the $W L$ is normalized on the water amount, due to its high variability among the aging times (example of calculations in Tables S2 and S3).

\section{Gel Permeation Chromatography}

Gel Permeation Chromatography was applied on bioplastic residues in order to determine the loss of molecular weight during composting. Samples were initially dissolved in chloroform (only MB, PBAT and PLA are dissolvable), then the analysis was carried out with Agilent 1200 series GPC equipment. Size exclusion chromatography (SEC) was performed in $\mathrm{CHCl}_{3}$ at $30{ }^{\circ} \mathrm{C}$ using an Agilent liquid chromatograph equipped with an Agilent degasser, an isocratic HPLC pump (flow rate $=1 \mathrm{~mL} / \mathrm{min}$ ), an Agilent autosampler (loop volume $=100 \mu \mathrm{L}$, solution conc. $=1 \mathrm{mg} / \mathrm{mL}$ ), an Agilent-DRI refractive index detector and three columns: a PL gel $10 \mu \mathrm{m}$ guard column and two PL gel Mixed-D $10 \mu \mathrm{m}$ columns (linear columns for separation of MW(PS) ranging from 500 to $107 \mathrm{~g} / \mathrm{mol}$ ). Polystyrene standards were used for calibration.

\section{Scanning Electron Microscopy}

Images of degraded and intact plastic pieces were collected with Scanning Electron Microscope (SEM), JSM 7200F JEOL emission field scanning electron microscope apparatus. The pieces of the tested materials were pre-treated before SEM analysis by submitting them to ethanol baths (one night 70\%, 2 baths $90 \%$ for 30 min and last bath $100 \%$ for $1 \mathrm{~h}$ ). After this procedure, the samples were dried passing 
to the critical point of $\mathrm{CO}_{2}$. Following the drying the samples were metallized with gold using JEOL device JFC $1100 \mathrm{E}$ ion sputter, fine coat. The metallization took place at $10 \mathrm{~mA}$ for $3 \mathrm{~min}$.

\section{Visual Inspection}

Plastic residues recovered from compost were reported in photographs to visually define the macroscopic changes of the material in accordance with the following criteria as described by EN 14045 (EN 14045, 2003): distribution of particle size, consistency of the material, discolouring, erosion signs on the surface and lateral erosion signs.

\section{Results and Discussion}

\section{Fourier Transform Infrared}

FTIR analysis provided an overview of the chemical bonds which characterize the tested materials, displaying the material through the main peaks (Fig. 1).

The FTIR spectrum of fresh MB (day 0) was characterized by the following peaks: $2921 \mathrm{~cm}^{-1}$ reliable to $\mathrm{CH}_{3}$; $1710 \mathrm{~cm}^{-1} \mathrm{C}=\mathrm{O}$ bounded to an alkyl group; $1269 \mathrm{~cm}^{-1}$ of ester linkage (PBAT); $1163 \mathrm{~cm}^{-1}$ corresponding to $\mathrm{CH}_{2} \mathrm{OH}$; $1150-950 \mathrm{~cm}^{-1}$ related to $\mathrm{C}-\mathrm{C}$ in n-alkanes; $1020 \mathrm{~cm}^{-1}$ corresponding to a disubstituted benzene (in butanediol terephthalate); $726 \mathrm{~cm}^{-1}$ reliable to skeletal stretch of butyl group $\left(\mathrm{CH}_{2}\right)_{\mathrm{n}=4}$. Moreover, smaller peaks were specifically related to PBAT: $2956 \mathrm{~cm}^{-1}$ assigned to the asymmetric stretching of $\mathrm{CH}_{2}, 1409 \mathrm{~cm}^{-1}$ and $1395 \mathrm{~cm}^{-1}$ relatable to trans$\mathrm{CH}_{2-}$ plane bending vibration [21]. The difference between fresh MB and PBAT was mainly in the peak $2961 \mathrm{~cm}^{-1}$ and in the peaks between 1150 and $950 \mathrm{~cm}^{-1}$, attributable to the presence of starch in MB molecule [22, 23].

The observed FTIR spectrum of the fresh PLA was similar to that reported previously with the same material $[24,25]$ : the peak at $1748 \mathrm{~cm}^{-1}$ is due to the asymmetric stretching of $\mathrm{C}=\mathrm{O}$ in lactide; $1450 \mathrm{~cm}^{-1}$ relatable to $\mathrm{CH}_{3}$ in alkanes, $1132 \mathrm{~cm}^{-1}$ which corresponds to $\mathrm{C}-\mathrm{C}$ stretching in alkanes; $1181 \mathrm{~cm}^{-1}$ which is the $\mathrm{C}-\mathrm{O}$ stretching in $-\mathrm{CH}-\mathrm{O}$ group; $1081 \mathrm{~cm}^{-1}$ of $\mathrm{C}-\mathrm{C}$ in n-alkanes; $755 \mathrm{~cm}^{-1}$ that identifies the crystalline phase of PLA $\left(866 \mathrm{~cm}^{-1}\right.$ is instead the wavenumber of amorphous PLA).

The FTIR spectrum of fresh LDPE showed specific peaks of this material: $2914 \mathrm{~cm}^{-1}$ and $2485 \mathrm{~cm}^{-1}$ which correspond to antisymmetric and symmetric $\mathrm{CH}_{2}$ stretching in n-alkanes, respectively. Then $1463 \mathrm{~cm}^{-1}$ is attributable to $\mathrm{CH}_{2}$ deformation in n-alkanes and $721 \mathrm{~cm}^{-1}$ is from methylene rocking. Finally, 1306 and $1351 \mathrm{~cm}^{-1}$ were observed in the LDPE spectrum, connected to the twisting and wagging deformation of the $\mathrm{CH}_{3}$ group [26].
The FTIR spectra collected at the end of the test (day 60) reported some peaks which are specific to all the degraded bioplastics. In the range between 3360 and $3240 \mathrm{~cm}^{-1}$, the band between 3380 and $3340 \mathrm{~cm}^{-1}$ is due to the stretching of the $\mathrm{OH}$ bond of the hydration by water molecules, while $3340-3290 \mathrm{~cm}^{-1}$ is assigned to $\mathrm{NH}$ group of amides. Thus, the broad peak in this range, which is more intense after 60 days, can be attributed to two main phenomena: the hydrolytic degradation of the biomaterial and the presence of proteinaceous substances due to the bacterial activity. In particular, the peak at $1635 \mathrm{~cm}^{-1}$ could be correlated to carboxylate ions $\left(\mathrm{R}^{-} \mathrm{COO}^{-}\right)$which formation is due to the activity of microorganisms [25]; moreover, after 60 days, the presence of the peak at $1550 \mathrm{~cm}^{-1}$ is attributable to proteinaceous material [16].

It's fair to observe that the spectra of 60 days degraded $\mathrm{MB}$ and pure PBAT were almost identical: they depict the same characteristic peaks. This indicates that on the one hand PBAT is subjected to degradation during the composting process both as pure material and as part of MB, and on the other hand that the presence of starch is almost negligible in the degraded MB (as indicated by the strong decrease of the peaks between 1150 and $950 \mathrm{~cm}^{-1}$ ). Regarding PLA, this material, after degradation, did not present significant changes with respect to the fresh material, as already observed in previous studies [27]. It is interesting to compare this observation with the hydrolytic degradation process of ester bonds, typically occurring in PLA, which always generate oligomers or monomers [28]. For this reason, it's fair to expect that during the degradation the peaks related to the bonds characterizing PLA do not change.

Finally, in LDPE just a slight sign of degradation was demonstrated by the two peaks at $1615 \mathrm{~cm}^{-1}$ and $1032 \mathrm{~cm}^{-1}$ which rise after composting; the first, as already observed in a previous study [29], is reliable to $\mathrm{C}-\mathrm{O}$ bond, and the second is a $\mathrm{CH}$ deformation.

\section{Experimental Weight Loss}

Figure 2 reports the experimental weight of the tested materials, expressed in grams of residual weight of both macro and micro $(<2 \mathrm{~mm})$ residues. In particular, in terms of experimental weight, after the degradation process, MB still presented some micro $(<2 \mathrm{~mm})$ and macro residues, with a size between the initial $5 \times 5 \mathrm{~cm}$ and $2 \mathrm{~mm}$ (Fig. 2a). In fact the weight loss experimentally measured with Eq. 1 was $45 \pm 4.7 \%$ (Fig. 2b). This value is not far from observations of previous studies operating in similar temperature conditions for a test period of 28 to 90 days [27, 30, 31]: these authors found that degradation in ranging between 30 and $55 \%$ [32]. It is already interesting to observe a difference with the weight loss of pure PBAT film, which was $8 \pm 1.6 \%$. 

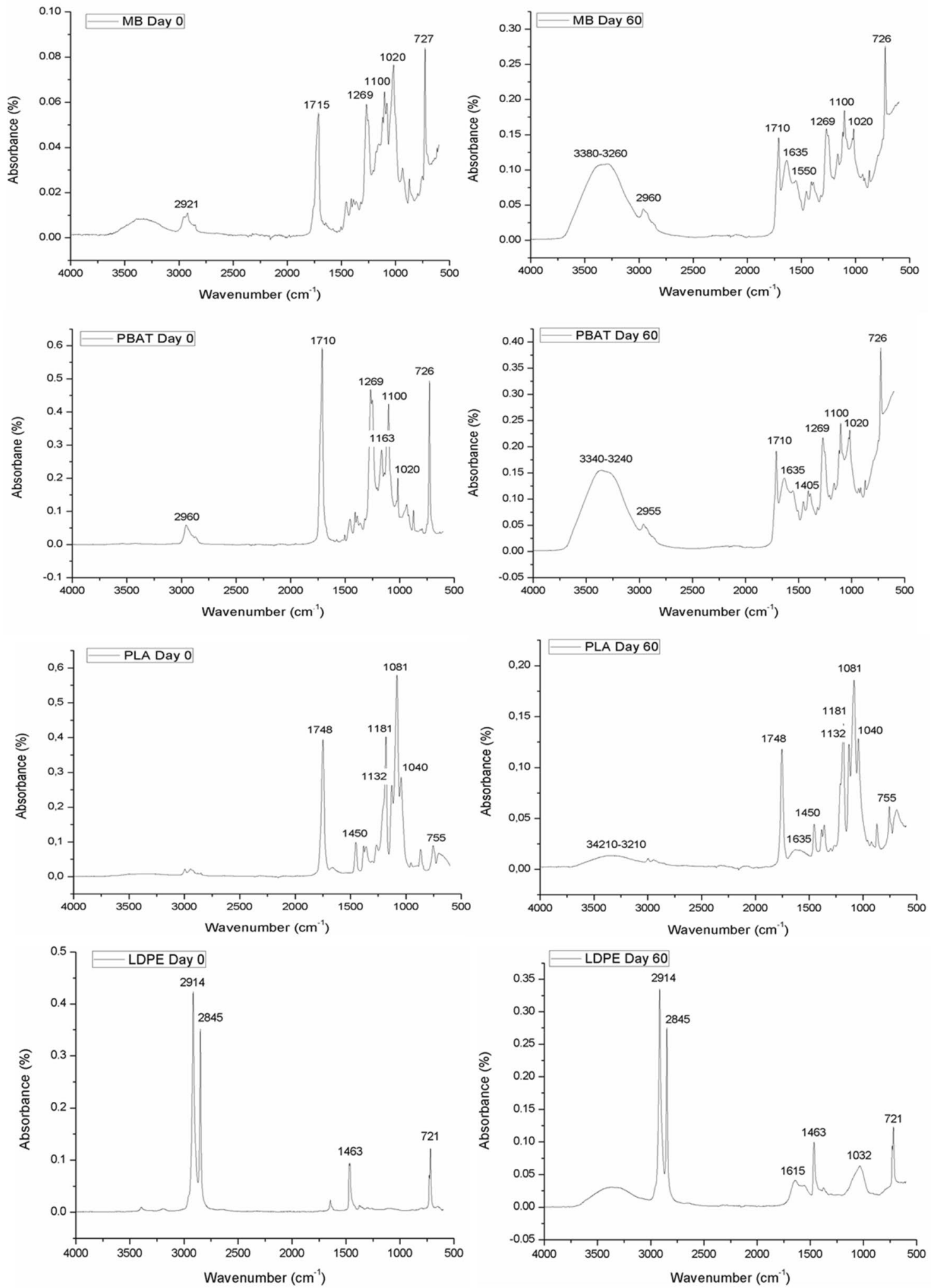

Fig. 1 Spectra of MB, PBAT, PLA and LDPE resulting from the FTIR of samples analysed before and in the end of the test, day 0 and 60 respectively 

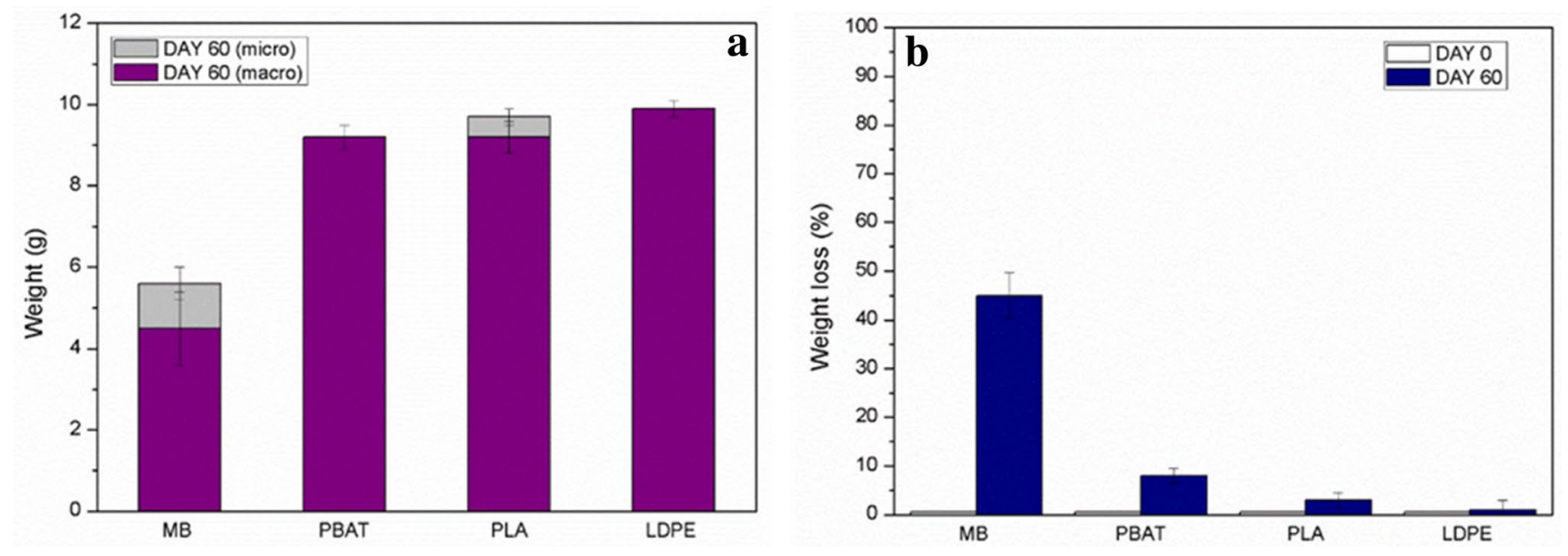

Fig. 2 Experimental weight of the tested materials, expressed in grams of residual weight of both macro $(5-2 \mathrm{~mm})$ and micro $(<2 \mathrm{~mm})$ residues (a) and in percentage of weight loss (b), elaborated in accordance with Eq. 1

Considering the rigid PLA, it was found that the degradation did not exceed $3 \pm 0.7 \%$. The observed trend of PLA requires to make a comparison with previous studies which found better degradation results. In a prolonged thermophilic phase ( $>30$ days) the degradation exceeded $90 \%$ in terms of experimental weight loss. [33, 34]. Conversely, it was found that mesophilic conditions (30-90 days) stop PLA degradation at around $10 \%[27,35,36]$. However, available studies on PLA were performed only on film material, with thickness ranging from 30 to $50 \mu \mathrm{m}$. Thus, the current research disclosed the importance of considering the thickness as significant variable in the degradation test, as well as composting conditions and the complexity of polymeric structure.

Besides MB, only PLA presented microplastic fragments after 60 days of composting; a further discussion of this phenomenon is provided in the next paragraphs.

\section{ThermoGravimetric Analysis}

The results derived from TGA analysis indicate that the major contribution in the MB weight loss was given by starch degradation: up to $88 \pm 2.9 \%$ as indicated in Fig. 3,
Fig. 3 Trend of weight loss of the tested materials, derived from TGA analysis in accordance with Eq. 3

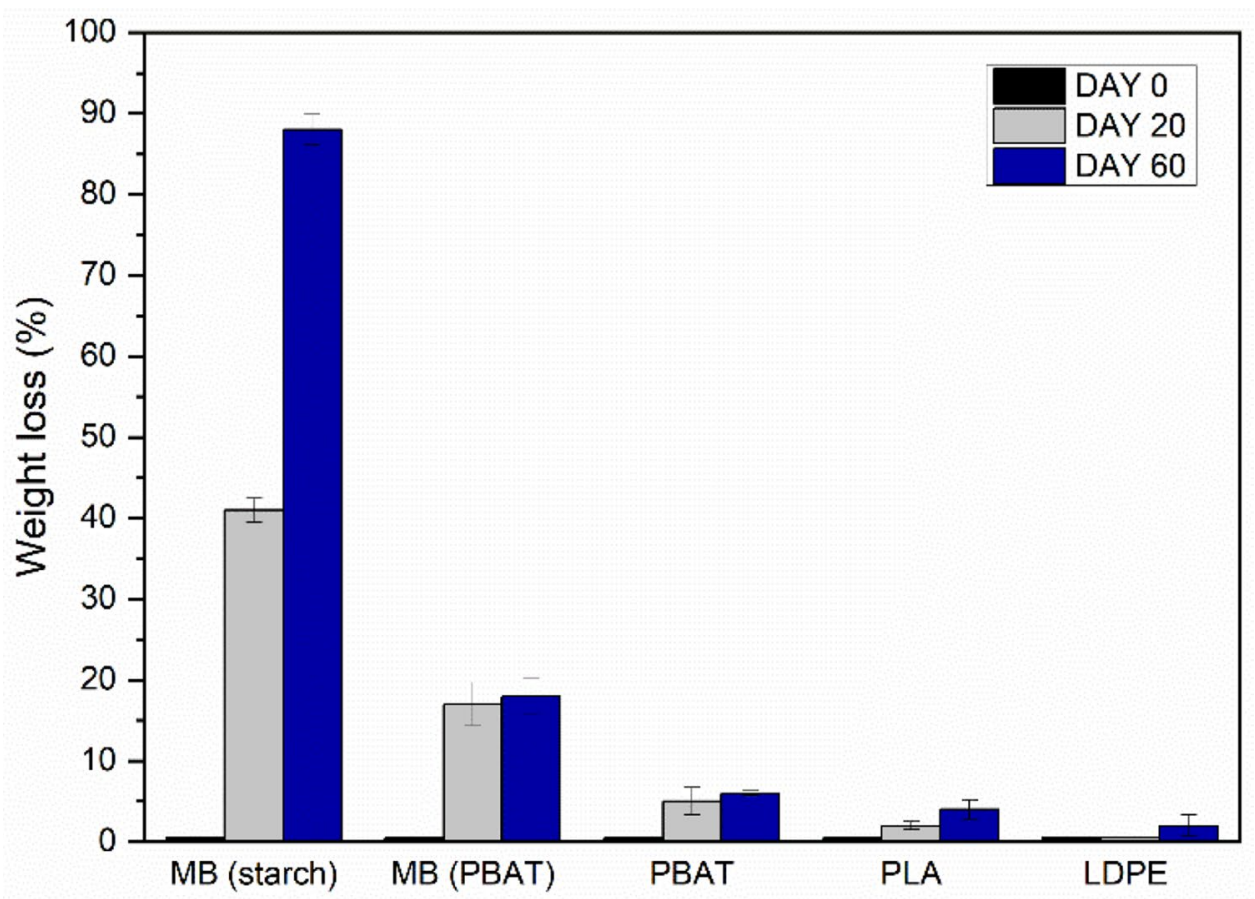


while this value is about $18 \pm 1.8 \%$ for PBAT (obtained by Eq. 3).

For MB it is also possible to provide an estimation of the global weight loss, considering that starch and PBAT constitute $30 \%$ and $70 \%$ of polymer respectively. The result estimated by these proportions is $39 \pm 2.1 \%$.

Table 1 Information derived from TGA analysis on the tested materials

\begin{tabular}{crlccc}
\hline & Day & $\mathrm{T}_{\text {peak }}\left({ }^{\circ} \mathrm{C}\right)$ & $\begin{array}{l}\text { Weight loss } \\
(\%)\end{array}$ & Water (\%) & Residue (\%) \\
\hline MB & 0 & 317 & - & - & - \\
(starch) & 20 & $303 \pm 0.8$ & $41 \pm 1.5$ & $3 \pm 0.9$ & $23 \pm 1.2$ \\
& 60 & - & $88 \pm 2.9$ & $9 \pm 2.4$ & $25 \pm 1.8$ \\
MB & 0 & 395 & - & - & - \\
(PBAT) & 20 & $396 \pm 0.6$ & $17 \pm 2.9$ & $3 \pm 0.9$ & $23 \pm 1.2$ \\
& 60 & $395 \pm 0$ & $18 \pm 1.8$ & $9 \pm 2.4$ & $23 \pm 1.8$ \\
PBAT & 0 & 395 & - & - & - \\
& 20 & $399 \pm 0.8$ & $5 \pm 1.7$ & $1 \pm 0$ & $10 \pm 1.3$ \\
& 60 & $400 \pm 0.3$ & $6 \pm 0.3$ & - & $10 \pm 0.3$ \\
PLA & 0 & 361 & - & - & - \\
& 20 & $349 \pm 1.6$ & $2 \pm 0.5$ & $2 \pm 0.5$ & $2 \pm 0$ \\
& 60 & $338 \pm 4.5$ & $4 \pm 1.2$ & $2 \pm 0.5$ & $1 \pm 0.9$ \\
LDPE & 0 & 467 & - & - & - \\
& 20 & $469 \pm 1.8$ & - & - & $2 \pm 1.3$ \\
& 60 & $470 \pm 0.3$ & $2 \pm 1.3$ & - & $2 \pm 1.3$ \\
\hline
\end{tabular}

As expected from the results of the experimental measurements previously described, the weight loss derived from the TGA for the other tested materials was not very high: $6 \pm 0.3 \%$ for pure PBAT, $4 \pm 1.2 \%$ for rigid PLA and lower than $2 \%$ for LDPE.

It is interesting to compare the results obtained by TGA with the weight loss experimentally measured. TGA results obtained for MB and PBAT, which present the major degradation among the materials, are $20 \pm 5 \%$ lower than experimental values. This discrepancy can be attributed to the higher precision of TGA analysis compared to a method based on a first visual recovery. Especially for $\mathrm{MB}$, the experimental weight loss method is highly limited by the naked eye recovery of micro fragments. Therefore, the smallest pieces are likely to remain into the compost and are not accounted in the residues weighted.

The $\mathrm{T}_{\text {peak }}$ (see Table 1) is a further parameter that can describe the degradation level of the investigated polymers. In $\mathrm{MB}$, the strong decrease of $\mathrm{T}_{\text {peak }}$ of the starch component (from $317^{\circ} \mathrm{C}$ for the undegraded MB down to $303{ }^{\circ} \mathrm{C}$ for the sample of MB collected 20 days after the beginning of the composting process) confirmed its stronger degradation with respect to the PBAT component. A progressive shift of $\mathrm{T}_{\text {peak }}$ to lower temperatures was found also in PLA: from $361{ }^{\circ} \mathrm{C}$ for the fresh material down to $338 \pm 4.5^{\circ} \mathrm{C}$ after 60 days of composting, indicating that a chain degradation also occurred for this polymer.

On the contrary, a slight increase of $\mathrm{T}_{\text {peak }}$ was observed for both PBAT and LDPE: this interesting phenomenon
Fig. 4 Trend of molecular weight loss $(\mathrm{g} / \mathrm{mol})$ for the tested bioplastics at the beginning, during (day 20) and in the end (day 60) of the test

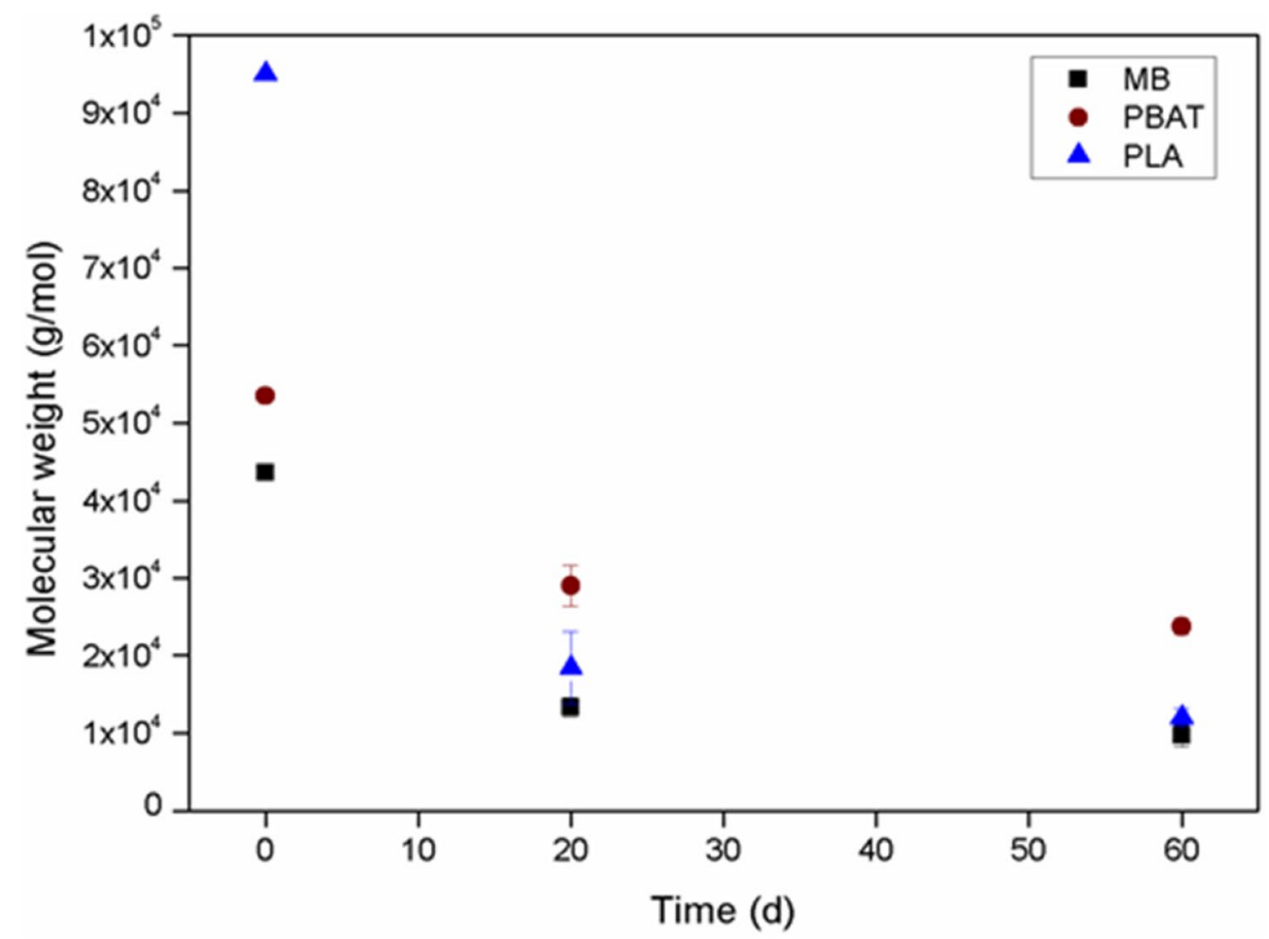


was already observed in earlier studies [37] and is probably due to cross-linking or recombination reactions of the biopolymer chains occurring during the first step of degradation.

\section{Gel Permeation Chromatography}

An important confirmation that biodeterioration and further depolymerization occurred in the four selected polymers was also provided by GPC analysis (Fig. 4).

Concerning MB, after 60 days of composting, a decrease of the average molecular weight of $75 \%$ was observed; this datum suggests the progressive fragmentation of MB into a mixture of oligomers and monomers [17].

Concerning PLA, the GPC data indicate that the molecular weight decreased from 9500 up to $1750 \mathrm{~g} / \mathrm{mol}$, which is consistent with the depolymerization process that gives the formation of simpler chains due to the hydrolysis occurrence [38].

A peculiar situation is instead related to pure PBAT. While TGA and weight loss did not highlight a strong degradation process, the GPC analysis reported a reduction of the molecular weight close to $50 \%$. This indicates that depolymerization started. The result seems in contrast with the slight increase of $\mathrm{T}_{\text {peak }}$ because both molecular weight and $\mathrm{T}_{\text {peak }}$ can be considered as indexes of the complexity of the material. It was expected that the decrease of the first index, which suggests a decomposition of the material into smaller polymer or oligomer chains, was accompanied by a decrease of the $T_{\text {peak }}$ [39]. However, as mentioned in the previous paragraph, in this case, $\mathrm{T}_{\text {peak }}$ increase can be attributed to cross-linking or recombination reactions occurring in PBAT polymer while degrading.

\section{Scanning Electron Microscopy}

Morphological analysis with SEM introduced an overview of the material biodeterioration and allowed to characterize the degraded residues through some interesting aspects.

In Fig. 5, fresh MB appears as a composite polymer with starch grains embedded in a flat film [19], which corresponds to PBAT, as confirmed by the micrograph of a flat surface of pure PBAT at day 0. Fresh PLA and LDPE are also characterized by a flat surface.

Concerning MB film, the disappearance of the starch grains embedded into the continuous matrix was evident already after the thermophilic phase of composting (day 20). Moreover, in this phase, the surface was fractured and colonized by different microorganisms. Some peculiar long chains distinguishable on the micrographs (Fig. 6a) are identifiable with fibres in the internal structure of the biopolymer, which constitute the strongest and less degradable part of the material. Thus, these fibres seem to emerge due to the progressive erosion of the material, as observed in previous studies dealing with plastic fibres [40, 41]. A further characteristic of the degraded material consisted of nanometric light dots which appeared on the surface after 60 days of composting (Fig. 6b1); the same nanodots were present on the surface of degraded PBAT (Fig. 6b2). Due to the small size, they can't be related directly to microbial organisms, but it's fair to identify them as metabolites excreted by the microorganisms after bioplastics assimilation.

A further peculiar feature of PBAT was the tendency of the surface to break (Fig. 6c): this aspect was already observed by previous authors [21, 42] and can be related to a physical degradation, for which effects are usually not immediately visible at a macroscopic level [43]. In the current case, these surface cracks may be considered as a first step of film disintegration that can result in the formation of nanoplastics (dimensions below $10 \mu \mathrm{m}$ ). Moreover, SEM analysis indicates that the pure PBAT was much less subjected to diffuse bacterial colonization than the PBAT in the MB.

Observing the degraded PLA, SEM micrographs illustrated the roughness of the surface and the appearance of pores after composting. Both are observations that characterize the degradation of the material [39, 44]. Further peculiarities were found. First, a porous structure with nanometric holes homogeneously distributed on the surface was observed and this shape is completely different from the flat surface before composting (Fig. 6d2). Holes on PLA surface have been observed by previous studies [45, 46], but in the current case this phenomenon is much more extensive. Secondly, as reported in Fig. 5e, an extensive bacterial colonization occurs on PLA. LDPE did not present particular visual changes after 60 days of composting.

\section{Visual Inspection}

Photographs of the tested materials showed some macroscopic physical changes occurring during composting (Fig. 7). The size reduction is visible for all the bioplastics, but especially in MB film. In the first weeks, the phenomenon was mainly related to the folding of the bioplastic sheets and to the increase of its stickiness due to the temperature of the thermophilic phase close to the melting point. Moreover, the disintegration was induced by the increasing fragility of the biomaterial and the concomitant biotic activity. The disintegration effect was widely observed in the residual MB recovered at the end of the test, as reported in Figs. 2a and S7 (around 25\% of the residues are microplastics; size below $2 \mathrm{~mm}$ ); finally, both macro and micro residues have colour and consistency similar to compost. 


\section{Day 0}
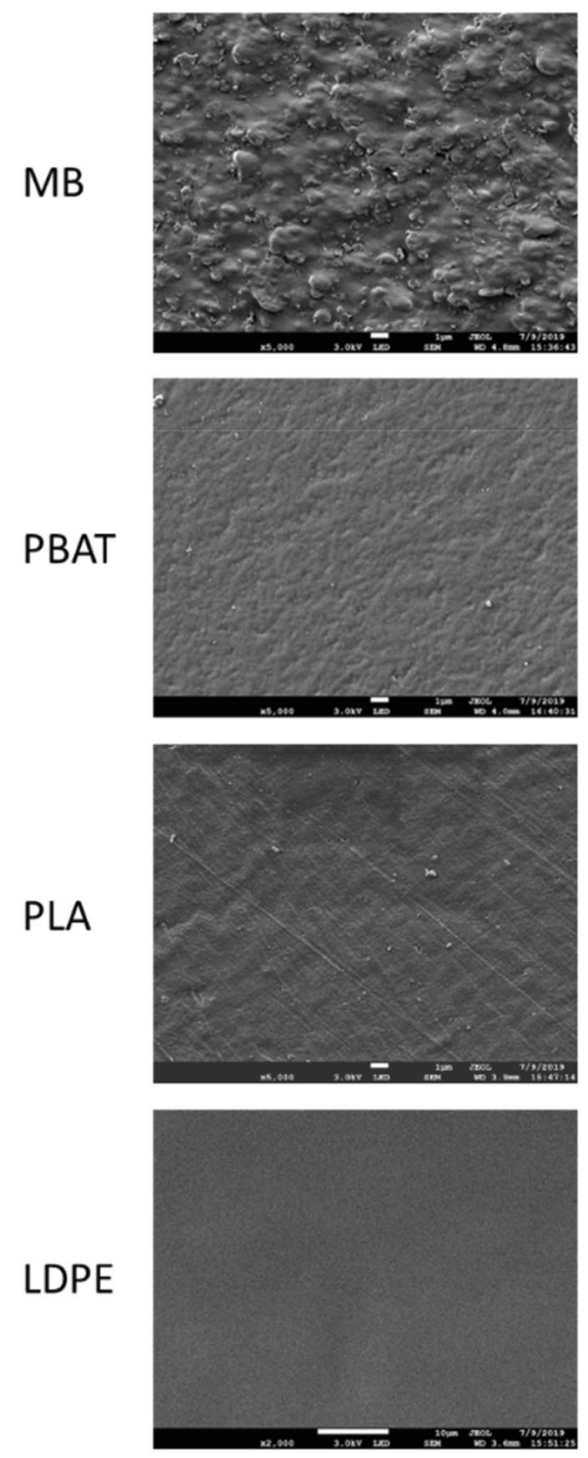

Day 20
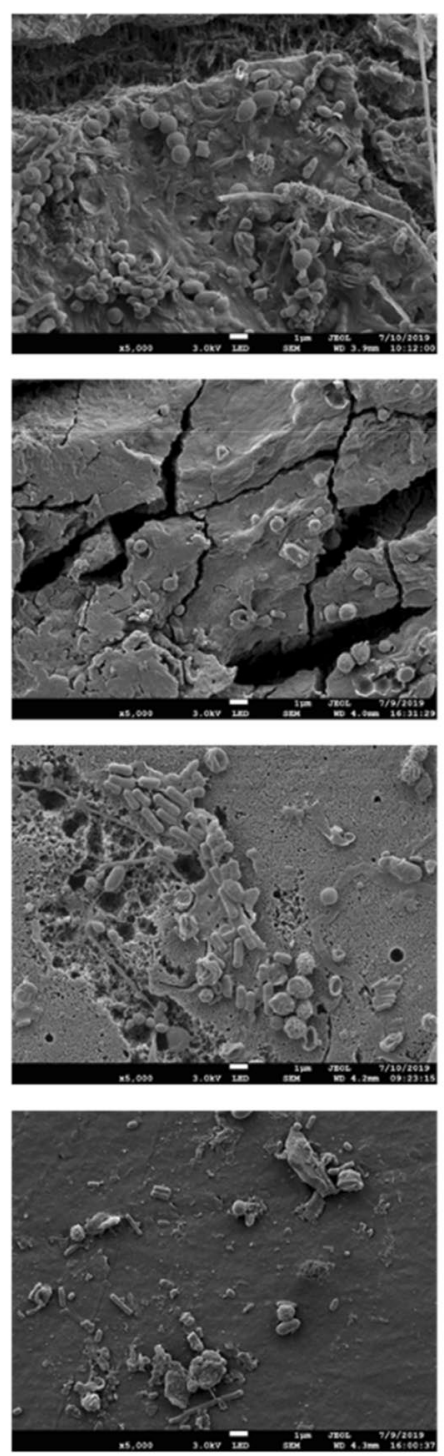

Day 60
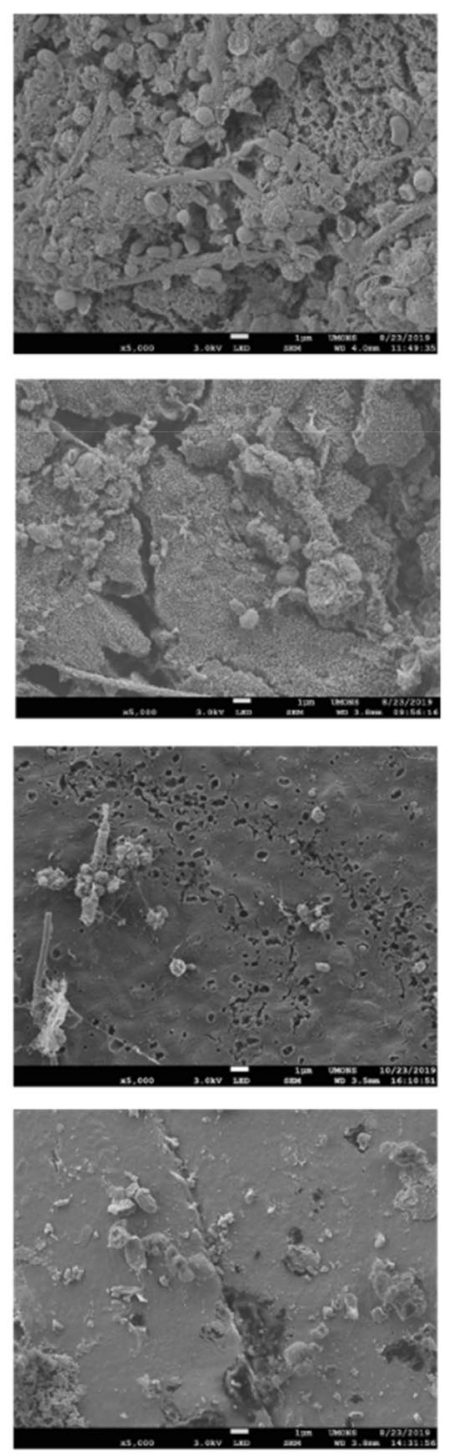

Fig. 5 SEM micrographs at different timings of the test carried out on the tested materials

Also PLA, as already found in earlier studies [39, 47], showed the tendency to disintegrate (Fig. 2a). A further observation (Fig. 7) on this thick bioplastic was the loss of transparency after 1 week of composting: this effect can be attributed to a progressive loss of the crystallinity. These aspects are considerable signs of abiotic and biotic activities involved in biodeterioration [37].

Finally, LDPE photographs reported an almost integer surface of LDPE (only the presence of compost residues is observable onto the film surface), still transparent and flat even after 60 days of composting.

\section{Conclusions}

The current research introduces a novelty among the studies related to bioplastics degradation: it investigates the difference of composting process conditions with respect to the guideline methodology and the variability of bioplastics thickness. The approach combining a variety of methodologies discloses a wide range of useful information about the degradation process.

The implementation of industrial composting conditions to study the plastic degradation highlights some interesting points. Signs of degradation are observable in all the tested materials. First, the decrease of molecular weight, 

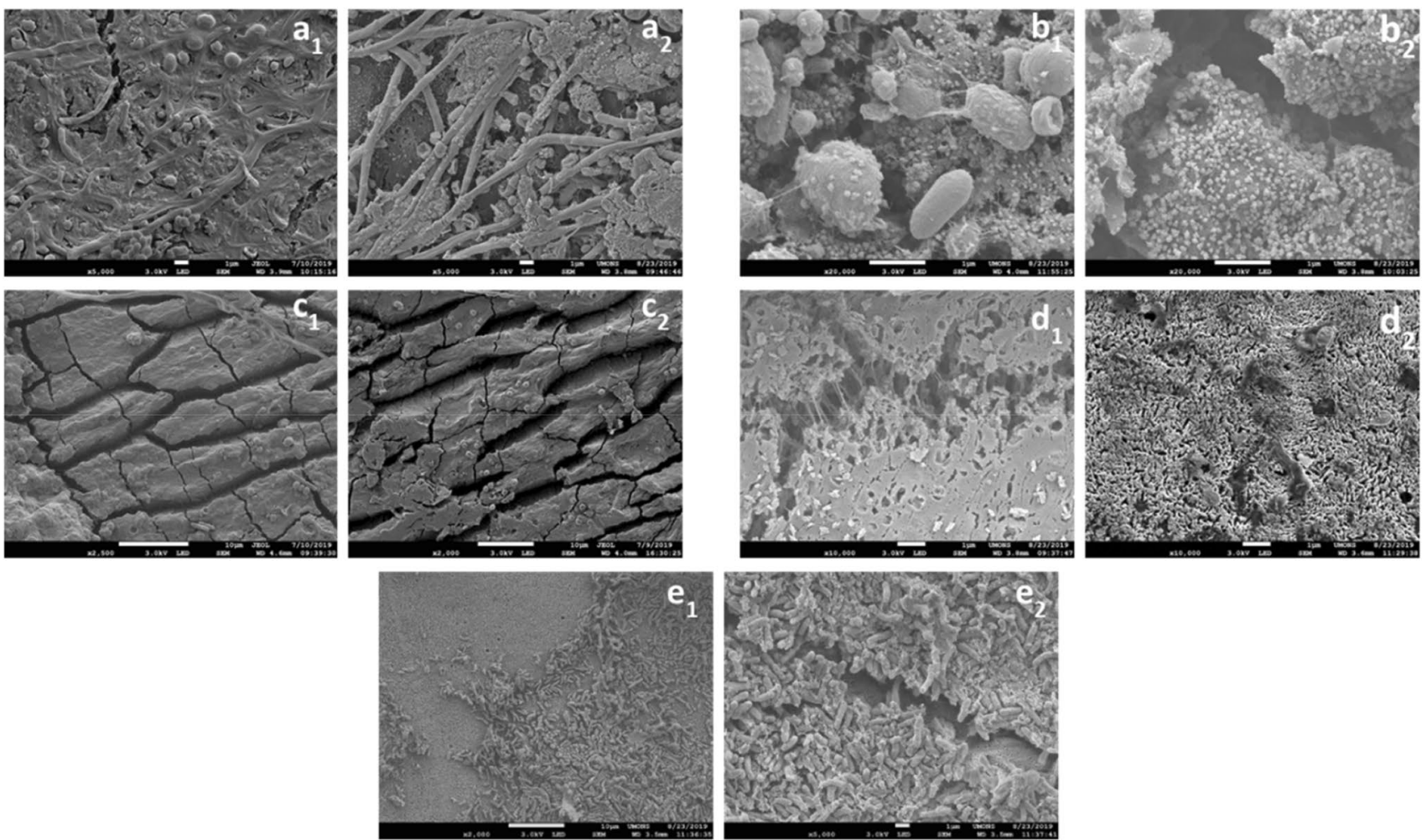

Fig. 6 Peculiar features observed with SEM analysis. a Filaments on MB surface (a1 is for day 20 and a2 for day 60). b Light dots on MB (1) and PBAT (2). c PBAT after 20 (c1) and 60 days (c2) of compost-

particularly accentuated for PLA and MB. Then, the peaks in the spectra assigned to proteinaceous material, relatable to biofilm formation on the surface of the bioplastics. Moreover, there are signs of erosion and disintegration visible from microscopic level (in PBAT) to macroscopic level (PLA and $\mathrm{MB})$, and nanoparticles detected with SEM micrographs on the surface of PBAT and MB residues. Finally, it was assessed the depolymerization into oligomer chains, assimilable by bacteria.

Film MB results in a quite high degradation. Importantly the degradation was higher for the PBAT present in MB than for pure PBAT: in fact, starch grains in MB degraded first, generating cavities which enhanced the degradation of the whole polymer. Despite this, it is noticeable from all the analyses that additional time is required for the complete degradation and therefore assimilability to compost. Furthermore, it emerged the issue of micro and nano fragments detected in the end of the test: further studies are recommended to carefully monitor their fate into the environment and to rethink regulation targets.

Rigid PLA exhibits key features of a progressive degradation, but the study disclosed the importance to include the ing. d Sponge structure of MB (d1) and PLA (d2). e Bacterial colonization on the surface of PLA

thickness as fundamental variable in the degradation process. Indeed, it was found that the combination of a 20 days thermophilic phase and the $500 \mu \mathrm{m}$ thickness of the material prevent a complete degradation within 2 months.

Finally, as reported in the introduction about the overview of the European Commission, the industrial composting plants have a mean thermophilic phase of 14-21 days. The current study found that a thermophilic phase of 20 days is not sufficient to ensure bioplastics degradation. This result is of great concern, because it highlights that the discrepancy between the standard conditions (e.g. EN 13432) and the industrial composting conditions is an issue to be accounted in the bioplastics management system.

If necessary, a proper degradation time in the industrial plants can be easily acquired by recirculating macro-residues of bioplastics after a refining treatment. To this purpose a last important issue emerged from the test of LDPE in composting; it showed a minor weight loss and not significative visual effects with respect to bioplastics. Moreover, the presence of LDPE in the retained material of refining treatments prevents the recirculation of the whole oversieved, which is therefore destined to incineration or landfilling. 


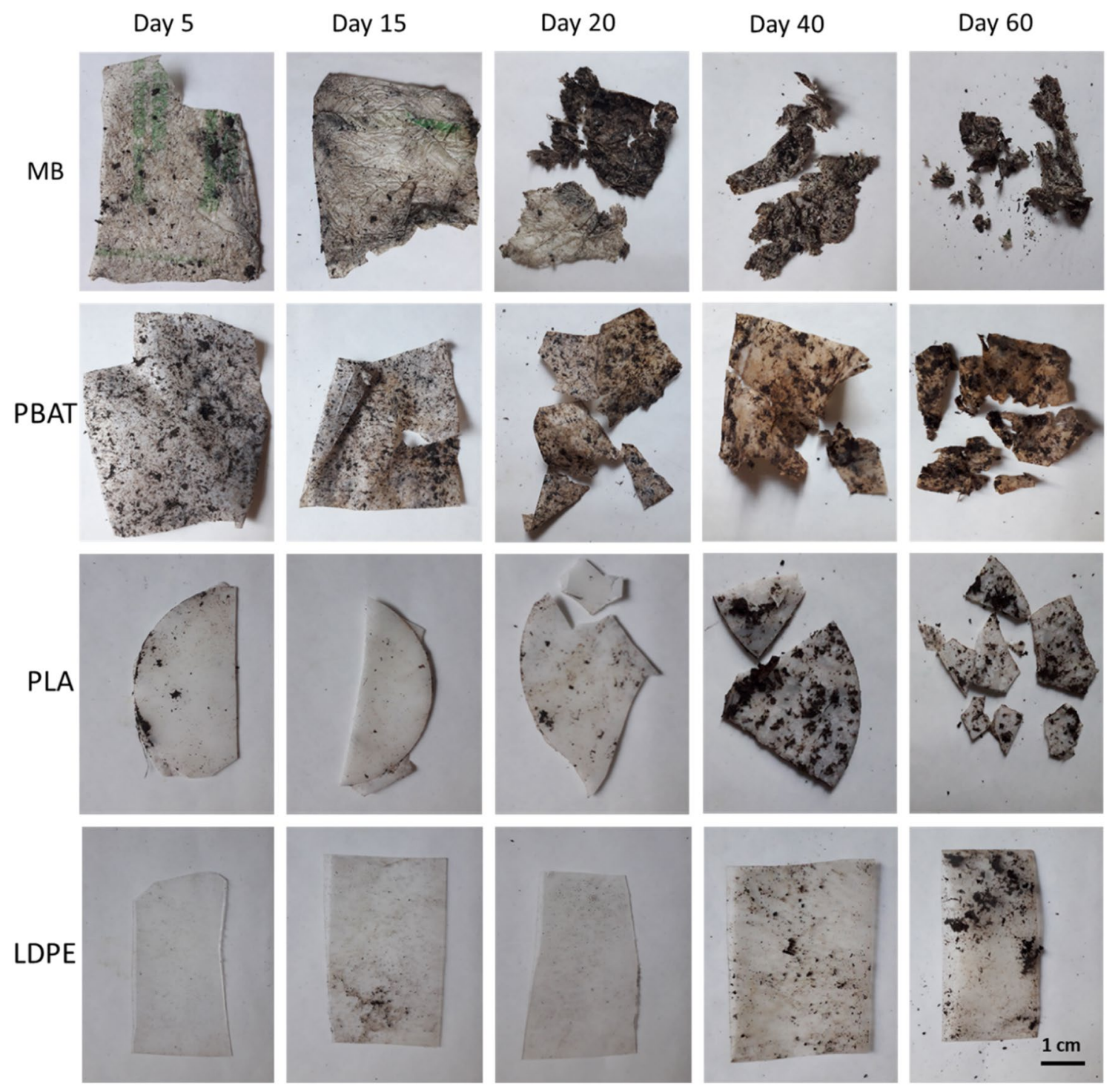

Fig. 7 Photographs of the tested materials at different timings of the degradation process

Thus, regulations should force the correct conferment of only bioplastics in the organic waste, to allow recirculation cycles of bioplastics and to improve the performance of the industrial plants.

Supplementary Information The online version of this article (https:// doi.org/10.1007/s10924-021-02098-2) contains supplementary material, which is available to authorized users.

Acknowledgements The experimental composting tests were carried out at Materia Nova in Parc Initialis, Avenue Nicolas Copernic 3, 7000 Mons, Belgium. The TGA, FTIR and GPC analyses were done at SMPC (UMONS). S. Benali acknowledges the European Community (FEDER) for general support in the frame of LCFM-BIOMAT. J.M.R is Chercheur Qualifié from Belgian FNRS agency.We want to thank Sébastien Moins for carrying out the GPC tests. Finally, we thank Nathan Puozzo from the Service of Biologie des Organismes Marins et Biominétisme (UMONS) for the SEM utilization.
Funding Open access funding provided by Università degli Studi di Firenze within the CRUI-CARE Agreement..

\section{Compliance with Ethical Standards}

Conflict of interest The authors declare that they have no conflict of interest.

Open Access This article is licensed under a Creative Commons Attribution 4.0 International License, which permits use, sharing, adaptation, distribution and reproduction in any medium or format, as long as you give appropriate credit to the original author(s) and the source, provide a link to the Creative Commons licence, and indicate if changes were made. The images or other third party material in this article are included in the article's Creative Commons licence, unless indicated otherwise in a credit line to the material. If material is not included in the article's Creative Commons licence and your intended use is not permitted by statutory regulation or exceeds the permitted use, you will 
need to obtain permission directly from the copyright holder. To view a copy of this licence, visit http://creativecommons.org/licenses/by/4.0/.

\section{References}

1. Narancic T, Cerrone F, Beagan N, O'Connor KE (2020) Recent advances in bioplastics: application and biodegradation. Polymers (Basel). https://doi.org/10.3390/POLYM12040920

2. EN 13432 (2000) Packaging — requirements for packaging recoverable through composting and biodegradation-test scheme and evaluation criteria for the final acceptance of packaging

3. ASTM (2011) ASTM D5338 standard test method for determining aerobic biodegradation of plastic materials under controlled composting conditions. Incorporating 98:1-6. https://doi.org/10.1520/ D5338-11.Copyright

4. ISO 20200 (2015) Test, standards publication plastics-determination of the degree of disintegration of plastic materials under simulated composting conditions in a laboratory-scale

5. Álvarez-Chávez CR, Edwards S, Moure-Eraso R, Geiser K (2012) Sustainability of bio-based plastics: general comparative analysis and recommendations for improvement. J Clean Prod 23:47-56. https://doi.org/10.1016/j.jclepro.2011.10.003

6. Italian Government (2017) Law number 123. http://www.gazze ttaufficiale.it/eli/id/2017/08/12/17G00139/sg. Accessed 3 Aug 2017

7. European Commission (2018) A European strategy for plastics in a circular economy. Communication from the commission to the European parliament the council the European economic and social committee and the committee of the regions

8. Emadian SM, Onay TT, Demirel B (2017) Biodegradation of bioplastics in natural environments. Waste Manage 59:526-536. https ://doi.org/10.1016/j.wasman.2016.10.006

9. European Commission (2000) Esempi di successo sul compostaggio e la raccolta differenziata Direzione generale Ambiente

10. Bioplastics European (2019) www.european-bioplastics.org. Accessed 15 Dec 2019

11. Pelmont J (2005) Biodégradationsetmétabolismes. Les bactériespuor le technologies de l'environnement, Les Ulis

12. Guo X, Wang J (2019) The chemical behaviors of microplastics in marine environment: a review. Mar Pollut Bull 142:1-14. https ://doi.org/10.1016/j.marpolbul.2019.03.019

13. Lucas N, Bienaime C, Belloy C et al (2008) Polymer biodegradation: mechanisms and estimation techniques-a review. Chemosphere 73:429-442. https://doi.org/10.1016/j.chemospher e.2008.06.064

14. Iovino R, Zullo R, Rao MA et al (2008) Biodegradation of poly(lactic acid)/starch/coir biocomposites under controlled composting conditions. PolymDegrad Stab 93:147-157. https://doi. org/10.1016/j.polymdegradstab.2007.10.011

15. Cai L, Wang J, Peng J et al (2018) Observation of the degradation of three types of plastic pellets exposed to UV irradiation in three different environments. Sci Total Environ 628-629:740-747. https ://doi.org/10.1016/j.scitotenv.2018.02.079

16. Bonhomme S, Cuer A, Delort AM et al (2003) Environmental biodegradation of polyethylene. PolymDegrad Stab 81:441-452. https://doi.org/10.1016/S0141-3910(03)00129-0

17. Siracusa V (2019) Microbial degradation of synthetic biopolymers waste. Polymers (Basel). https://doi.org/10.3390/polym11061066

18 Bastioli C (1998) Properties and applications of mater-Bi starchbased materials. PolymDegrad Stab 59:263-272

19. Ruggero F, Carretti E, Gori R et al (2020) Monitoring of degradation of starch-based biopolymer fi lm under different composting conditions, using TGA, FTIR and SEM analysis. Chemosphere 246:125770. https://doi.org/10.1016/j.chemosphere.2019.125770

20. ISO 14855-2 (2018) Determination of the ultimate aerobic biodegradability of plastic materials under controlled composting conditions - method by analysis of evolved carbon dioxide

21. Weng Y, Jin Y, Meng Q et al (2013) Biodegradation behavior of poly (butylene adipate-co- terephthalate) (PBAT), poly (lactic acid) (PLA), and their blend under soil conditions. Polym Test 32:918-926. https://doi.org/10.1016/j.polymertesting.2013.05.001

22. ElfehriBorchani K, Carrot C, Jaziri M (2015) Biocomposites of Alfa fibers dispersed in the mater- $\mathrm{Bi}{ }^{\circledR}$ type bioplastic: morphology, mechanical and thermal properties. Composits A 78:371379. https://doi.org/10.1016/j.compositesa.2015.08.023

23. Mihaela E, Todica M, Cioica N et al (2018) IR investigation of some degraded starch based biopolymers. Mater Today 5:15902-15908

24. Tabasi RY, Ajji A (2015) Selective degradation of biodegradable blends in simulated laboratory composting. PolymDegrad Stab 120:435-442. https://doi.org/10.1016/j.polymdegradstab .2015 .07 .020

25. Arrieta MP, López J, Rayón E, Jiménez A (2014) Disintegrability under composting conditions of plasticized PLA-PHB blends. PolymDegrad Stab 108:307-318. https://doi.org/10.1016/j.polym degradstab.2014.01.034

26. da Silva DJ, Wiebeck H (2017) Using PLS, iPLS and siPLS linear regressions to determine the composition of LDPE/HDPE blends: a comparison between confocal Raman and ATR-FTIR spectroscopies. VibSpectrosc 92:259-266. https://doi.org/10.1016/j.vibsp ec.2017.08.009

27. Massardier-Nageotte V, Pestre C, Cruard-Pradet T, Bayard R (2006) Aerobic and anaerobic biodegradability of polymer films and physico-chemical characterization. PolymDegrad Stab 91:620-627. https://doi.org/10.1016/j.polymdegradstab .2005 .02 .029

28. Benali S, Aouadi S, Dechief AL et al (2015) Key factors for tuning hydrolytic degradation of polylactide/zinc oxide nanocomposites. Nanocomposites 1:51-61. https://doi. org/10.1179/2055033214Y.0000000007

29. Delacuvellerie A, Cyriaque V, Gobert S et al (2019) Theplastisphere in marine ecosystem hosts potential specific microbial degraders including Alcanivoraxborkumensis as a key player for the low-density polyethylene degradation. J Hazard Mater 380:120899. https://doi.org/10.1016/j.jhazmat.2019.120899

30. Mohee R, Unmar GD, Mudhoo A, Khadoo P (2008) Biodegradability of biodegradable/degradable plastic materials under aerobic and anaerobic conditions. Waste Manage 28:1624-1629. https://doi.org/10.1016/j.wasman.2007.07.003

31. Accinelli C, Saccà ML, Mencarelli M, Vicari A (2012) Deterioration of bioplastic carrier bags in the environment and assessment of a new recycling alternative. Chemosphere 89:136-143. https://doi.org/10.1016/j.chemosphere.2012.05.028

32. Ruggero F, Gori R, Lubello C (2019) Methodologies to assess biodegradation of bioplastics during aerobic composting and anaerobic digestion: a review. Waste Manage Res. https://doi. org/10.1177/0734242X19854127

33. Kale BG, Auras R, Singh SP, Wiley J (2007) Comparison of the degradability of poly (lactide) packages in composting and ambient exposure conditions. PackagTechnolSci 20:49-70

34. Pradhan R, Misra M, Erickson L, Mohanty A (2010) Compostability and biodegradation study of PLA-wheat straw and PLA-soy straw based green composites in simulated composting bioreactor. BioresourTechnol 101:8489-8491. https://doi. org/10.1016/j.biortech.2010.06.053

35. Song JH, Murphy RJ, Narayan R et al (2009) Biodegradable and compostable alternatives to conventional plastics. Philos Trans R Soc B. https://doi.org/10.1098/rstb.2008.0289 
36. Shrestha A, van-Eerten Jansen MCAA, Acharya B (2020) Biodegradation of bioplastic using anaerobic digestion at retention time as per industrial biogas plant and international norms. Sustainability. https://doi.org/10.3390/su1210423

37. Kale G, Auras R, Singh SP, Narayan R (2007) Biodegradability of polylactide bottles in real and simulated composting conditions. Polym Test 26:1049-1061. https://doi.org/10.1016/j. polymertesting.2007.07.006

38. Pantaloni D, Shah D, Baley C, Bourmaud A (2020) Monitoring of mechanical performances of flax non-woven biocomposites during a home compost degradation. PolymDegrad Stab 177:109166. https://doi.org/10.1016/j.polymdegradstab .2020 .109166

39. Luzi F, Fortunati E, Puglia D et al (2015) Study of disintegrability in compost and enzymatic degradation of PLA and PLA nanocomposites reinforced with cellulose nanocrystals extracted from PosidoniaOceanica. PolymDegrad Stab 121:105-115

40. Pivokonsky M, Cermakova L, Novotna K et al (2018) Occurrence of microplastics in raw and treated drinking water. Sci Total Environ 643:1644-1651. https://doi.org/10.1016/j.scito tenv.2018.08.102

41. Afzaluddin A, Jawaid M, Salit MS, Ishak MR (2019) Physical and mechanical properties of sugar palm/glass fiber reinforced thermoplastic polyurethane hybrid composites. J Mater Res Technol 8:950-959. https://doi.org/10.1016/j.jmrt.2018.04.024

42. Wang H, Wei D, Zheng A, Xiao H (2015) Soil burial biodegradation of antimicrobial biodegradable PBAT films. PolymDegrad Stab 116:14-22. https://doi.org/10.1016/j.polymdegradstab 2015.03.007
43. Duval C (2004) Matériaux dégradables In Matières plastiques et environnement-recyclage, valorisation, biodégradabilité, écoconception. DUNOD, Paris

44. Petinakis E, Liu X, Yu L et al (2010) Biodegradation and thermal decomposition of poly(lactic acid)-based materials reinforced by hydrophilic fillers. PolymDegrad Stab 95:1704-1707. https://doi. org/10.1016/j.polymdegradstab.2010.05.027

45. Bijarimi M, Ahmad S, Rasid R (2013) Mechanical, thermal and morphological properties of poly(lactic acid)/natural rubber nanocomposites. J ReinfPlast Compos 32:1656-1667. https:// doi.org/10.1177/0731684413496487

46. Valerio O, Misra M, Mohanty AK (2017) Sustainable biobased blends of poly(lactic acid) (PLA) and poly (glycerol succinate-: co -maleate) (PGSMA) with balanced performance prepared by dynamic vulcanization. RSC Adv 7:38594-38603. https://doi. org/10.1039/c7ra06612k

47. Kale G, Auras ÆR, Paul ÆS (2006) Degradation of commercial biodegradable packages under real composting and ambient exposure conditions. J Polym Environ 14:317-334. https://doi. org/10.1007/s10924-006-0015-6

Publisher's Note Springer Nature remains neutral with regard to jurisdictional claims in published maps and institutional affiliations. 